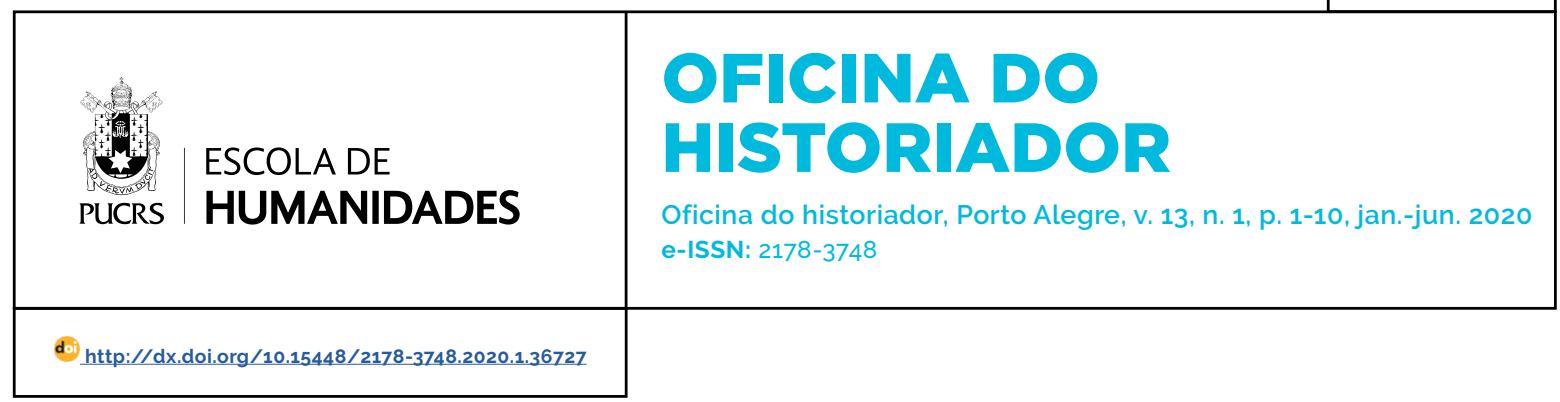

DOSSIÊ

\title{
Archaeology and Ideology in a 'postmodern' environment: material remains of ideological claims
}

\author{
Arqueologia e Ideologia em um ambiente 'pós-moderno': restos materiais de \\ reinvindicações ideológicas
}

John Gabriel O'Donnell ${ }^{1}$ orcid.org/0000-0002-6766-8588 jgabrielodonnell@gmail.com

Recebido em: 27 dez. 2019. Aprovado em: 1 fev. 2020. Publicado em: 14 jun. 2020.
ABSTRACT: According to scholar Fredrik Fahlandar, postmodernism has caused an intellectual identity crisis throughout the humanities. Using his chapter on Postmodern Archaeologies as a guide, this essay attempts to address some of the ways in which archaeology and the other social sciences has actually benefited from the scrutiny of postmodernist criticism, while at the same time maintaining its usefulness and insisting on its ability to avoid a relativistic approach to its research questions. The essay particularly emphasizes archaeology's on-going relationship to the study of ideology, as both evident within the archaeological record itself and also its influence on the researchers conducting the investigations. KEYWORDS: Theory of archaeology. Ideology. Postmodernism.

RESUMO: Segundo o estudioso Fredrik Fahlandar, o pós-modernismo causou uma crise de identidade intelectual em todas as humanidades. Usando seu capítulo sobre Arqueologias pós-modernas como guia, este ensaio tenta abordar algumas das maneiras pelas quais a arqueologia e as outras ciências sociais realmente se beneficiaram do escrutínio das críticas pós-modernas, enquanto, ao mesmo tempo, mantém sua utilidade e insiste em sua capacidade de evitar uma abordagem relativista de suas questões de pesquisa. O ensaio enfatiza particularmente a relação contínua da arqueologia com o estudo da ideologia, como evidente no próprio registro arqueológico e também sua influência nos pesquisadores que conduzem as investigações.

PALAVRAS-CHAVE: Teoria da arqueologia. Ideologia. Pós-modernismo.

Since the initiation of it's usage in the early 19th century, ideology has always, in one form or another, been about the expression of or concentrated study of ideas and, fundamentally, the nature of those ideas' relationships to reality. Over the course of the term's development and usage, the word ideology has become ever more associated with ideational relations to realities very often pertaining to power structures (political), social stratification, economic laws, and religious configurations (sometimes combining more than one of these). The major epistemological debate regarding ideology/ideologies has been this very question: whether ideas (especially those arranged to describe structural and universal truths) bear any significant resemblance to the actual material world.

Naysayers and skeptics of this possibility of an ideology acting as an accurate mirror-like reflection of reality tend to view ideology in a pejorative sense, going so far as to define its very use as the application of ideas which cannot be proven (GEERTZ, 1973, p. 196). We can look as far back 
to Napoleon Bonaparte brandishing the term in this cynical way when describing the pie-in-thesky metaphysics of Enlightenment philosophers (ALTHUSSER, 1971, p. 171). If on the other hand, one is open to the daring possibility that ideas can truthfully describe human realities with some level of utility and fidelity, an ideology or/and ideologies can be quite attractive if not absolutely essential to understanding and confronting the realities of past, present and future of the human condition.

These two very different views of ideological structures have had their ardent supporters and detractors over the years (one could even make the case that the deadlock goes all the way back to Plato's forms and the empirically-oriented approach championed by Aristotle), and certainly specific historico-intellectual movements have dictated their refinement and criticism in the debate: evolutionism, nihilism, cognitive behaviorism, phenomenology, romanticism, etc. It must be noted, however, that there is ample room for the possibility of a truthful ideology to co-exist alongside various false ideologies. In this sense, the larger, 'more accurate' ideological paradigm would subsume, even likely explain, the existence of the lesser, ill-conceived minor ideologies in a sort of conceptual Russian doll: the all-encompassing Ideology containing the other ideologies snugly inside. Most notably, marxist thinking and its related approaches, such as material historicism, have laid out and developed this very claim. The marxist approach, discussed vis-a-vis archaeology later, offers itself as an explanation for the very raison d'état for the various political, religious, aesthetic and psychological ideologies that develop within the larger structure of historical materialism. Its persistent presence in the discussion indicates precisely its formidable durability as a useful departure for analysis of history; however its emphasis on class and means of production often find it ill-suited for addressing social and cultural questions that don't have these economic elements at their core.

So where exactly does postmodernism sit in relation to the concept of ideology? Rather than being defined as a solid and fixed set of beliefs, postmodernism seems to behave more like the essence of an era (our era), a sort of ideological malaise, disorientation or even exhaustion. As Fredrik Fahlander puts it, "Postmodernism can be characterized as an antithesis of the modern. Instead of seeking order, coherence, regularity, and general laws, postmodernism celebrates diversity and plurality, fragmentation, and indeterminacy" (FAHLANDER, 2014, p. 1).

Many have tried to historicize the development of postmodernism, finding its root cause in the existentially disastrous events of the 2oth century: two world wars, amid countless other conflicts utilizing an industrial level of violence; the failure of the promise of technology to offer the anticipated life of material fulfillment and self-empowerment; and the general loss of enthusiasm and faith in both socialist state-craft and neo-conservative economic liberalism as durable social blueprints. The pervasive intellectual, social and stylistic climate of incertitude spread like a fog and came to be labelled postmodernism (meaning following the more selfconscious 'modern era' between the world wars).

Some typical keywords and turns of phrase that pop up when describing the postmodern position are multivocality, relativity of facts, the individual and the particular. This factual elasticity leads to the terrifyingly cynical belief that meaning itself may only be the fantastical and convoluted construct of humanity's collective ego. Being that a good postmodernist tends to see all things as having equivalent values of universal meaning, postmodernism views ideologies very much in this fashion: as groupings of ideas held in common by societal subgroups that largely communicate their beliefs about themselves and their beliefs about their relationship to the outside world in an insular nature. This 'echo chamber' description of ideologies does not hold out much hope that any of the ideological paradigms would be usefully reflective of any really tangibly-based descriptions of reality. For the postmodernist, the ideological schools might be interesting to study in their own right, but only as a sort of intellectual exercise into curiosities of human behavior. Perhaps they could 
even be used in a more practical way to gauge the collective temperatures of certain political, social and cultural movements within a given fixed historical context. However, the once inspiring possibility that an all-encompassing ideological framework could hold any water when applied broadly and be held in credence and applicable in all cases would be completely antithetical to the postmodernist mindset, unless, of course, that very ideological model was a model of existentialist relativism of information and experience.

The methods of archaeology, which by definition deal directly with physical material culture and are the subject of this essay, provide a fascinating litmus test for the existence of a universal ideology (with a capitalized I): What does the material evidence suggest about the likelihood of its existence? Secondly, the plethora of minor ideologies contextualized in their temporal and geographic places in excavation can be addressed: What does the material evidence offer up in terms of elucidating what these particular people might have believed about their reality? What ideologies were at play throughout their material lives and how did these ideologies inform, confine, inspire and contradict those physical realities? As Fahlander indicates in his text, postmodernism questions the methodology and interpretation from the researchers themselves, as well as their conclusions regarding the societies under investigation. By using the concept of ideology vis-a-vis the archaeological record, we can recognize that both the ideological reality of the research subject (i.e., the user, producer, owner or inhabitant of the material remains under study) must also be combined with the ideological context of the researcher (their background, social class, training and purported purpose for conducting the research). Gathering a nuanced body of biographical understanding is likely to be extremely difficult to distill with great clarity and methodologically impossible to prove with certainty, but, nonetheless, remains essential to pursue.

Perhaps postmodernism is a natural state for the moment: the collective, residual hangover from the crash that was the disappointing violence of the 2oth century's failures. But rather than reactively throwing out the possibility of acquiring knowledge, we could constructively view this movement as a pivotal moment in societal selfreflection. Clearly some of our widely-held ideas have been abusively erroneous, but rather than committing intellectual suicide, we can step back from the ledge, reflect on our current situation, find therapy in the form of the many intellectual traditions that still do shed a little light our reality and move ahead. One obvious note of criticism of the postmodernist model is simply that no one behaves like a postmodernist. People continue to live in a world of values, rules, restraints, expectations, liberties and decision making or at least we behave as such and continue to express our beliefs, fears and aspirations in semiotics and the shared symbols that embody culture. Though we have often underestimated the complexity of these realities, we behave as if we acknowledge the existence of truths, however ideational, selfpromulgating or mythologizing they might be. Archaeology - the study of human behavior in tangible form - is flush in evidence of ideology and ideologies and material objects' constitution are informed and in turn inform, a variety of commonly-held human beliefs. Using Fahlander's essay on postmodern archaeology as our guide, let us see if we can't come to some conclusions about how to conduct archaeology in a way that neither diminishes complexity and multivocality (ideologies), without ignoring the fact that these voices, in order to be heard, must be echoing off some kind of material existence. Whereas the historian deals largely in the written language; pure signs, pure symbolism; the archaeologist is both freed from the ambiguity of pure language and also handicapped by the rigidity of access to the wider material world. In terms of the study of or divination of the belief in or existence of ideologies this epistemological challenge remains exciting and formidable and archaeology is an essential component.

Although Fredrik Fahlander, in his 2014 essay "Postmodern Archaeologies", doesn't mention ideology by name, the fact that he is directly addressing the flood of skepticism regarding 
archaeology's very ability to contribute to a body of truth (a structure/superstructure), put his work squarely within the on-going conversations regarding the nature of ideology. It's almost as if we could take the well-worn names of the two distinct lines of archaeological thinking: processual (when performed correctly archaeology can reflect an absolute reality) and post-processual (the best archaeology can do is to provide a means of reflection about ourselves and our relationship to the past) and replace them with Paul Ricouer's two brands of ideologies: structuralist (a truthful ideology should be reflected in the archaeological record) and humanist (because the evergrowing family of ideologies change over time and throughout societies the best archaeology could do is provide a means of reflection about a specific set of beliefs that were held to be true by a specific set of people at a specific moment in time) (RICOUER, 1986, p. 68). Just like Ricouer's ideological distinctions, post-processual or postmodern archaeology have no single history: although it may offer multiple, personalized histories as an option. Processual archaeology, on the other hand, concretely reflects the single history of a universal material development: although it will inevitably fall short in describing it accurately due to the clumsiness of techniques and methods and the ideological (lower-case 'i') bias of its researchers. The stark difference is it attempts to uncover a single truth, rather than describe many truths given equivalent value.

So in what ways could the material that the archaeologist confronts provide evidence of ideology in the material record? That again, depends into which current of ideological theory the researcher is tacking. In the marxist-derived model, the material culture remains of any society would represent physical components of the power structures at work in society. They could be base component parts of productive operation (a spindle whorl, for example), an object to maintain productive structures in balance or obtain new resources, either directly or ritualistically (an arrow head or a tumi knife), or an object of pure ideological symbolism meant to act as a mental representative of productive forces and affix the status quo (a religious symbol or object of fashion). It is important to remember that these objects need not be, and rarely are, designed and constructed by their creators with these direct objectives in mind: the overarching ideology that pervades the given social order makes any such premeditation unnecessary in the marxist model.

Althusser calls these objects and the activities that utilize them (personal habits, rituals, social exchanges), 'hardware', and this is a very useful concept (ALTHUSSER, 1971, p. 186). When examining an archaeological object (let's say - a standard push lawn mower) it is very common to ask - What was it used for? What was its function? Easy enough: to cut the grass and keep the yard from becoming overgrown. But in the Althussian mode the more poignant questions ought to be - What role did it play ideologically? How did the object fulfill its conceptual duties? In this case, it acts as a buffer of activity between the owner of the object (a hard-working suburban homeowner) and his social role (a productive, satisfied member of his class). The act of mowing the lawn exudes the pride of homeownership, a conduit of activity on a hard-won day off from the 9-to-5 workweek, tangible engagement with mechanics and masculine pursuits, and by maintaining the front lawn in an organized and trimmed manner, the neighborhood maintains its sense of order: a logically manicured rather than wildly untamed environment. Through the use of the lawn mower its action has a ripple effect: reminding the neighbor that his grass could also use a trim before the weekend is over and sending the message down the line. An official set of rules and regulations is not necessary when the symbolic vocabulary is universally agreed upon.

In Bruno Latour's Action-Network-Theory the existence of material objects take on an even more pronounced role. They are not only tools used up by the social creatures and discarded, but are active participants in the social network: influencing, instigating and incorporated into the behavior in an integral way. Their excavation could 
be seen as more akin to finding skeletal remains which would indicate the past presence of a full body - in their case, the 'body' would be the network of their involvement. In that sense, for Latour, speaking of social development without including its 'component things' is a non-starter:

\begin{abstract}
Sociologists will claim that when they appeal to the durability of social ties they bring in something that really possesses the necessary durability, solidity, and inertia. It is 'society', or 'social norm', or 'social laws', or 'structures', or 'social customs', or 'culture', or 'rules', etc., they argue, which have enough steel in them to account for the way it exerts its grip over all of us and accounts for the unequal landscape in which we are toiling. It is, indeed, a convenient solution but does not explain where their 'steely' quality is coming from that reinforces the weak connections of social skills. (LATOUR, 2005, p. 67)
\end{abstract}

In a scenario of a universal structuralist view of ideology and its functioning dependence on material objects the great distances in time and culture often cited as the challenge of archaeology, comes to be seen not so much as an insurmountable barrier, but even perhaps as epistemological benefit. As we see with contemporary culture (and our weekend warrior, lawn mower using cohort), it is rare that the users of objects, buildings, vehicles, art and fashion consider the purpose of the object in its wider 'structural' sense. Sometimes the contemporary voices can become symbolic red herrings leading to dry lake beds rather than an explanation bearing any relation to reality. If the archaeologist can accurately determine what the practical use of an object was (this is not always easy), and we know a little about the social context in which its user lived (even more difficult, but possible), than we might be able to arrive at some reasonable conclusions about how this object fulfilled its primary ideological role in this specific instance. In fact, having the user explain to us their ideas about the object's use - while providing incredible data regarding the personality, ontology and biography of the user - would provide very little information regarding the object's true function in the social order (these biographical questions are within the milieu of our second, humanistic definition of ideology).

When Fahlandar says: "Postmodernism emphasizes the belief that there is no reliable way to establish 'how it once was' by scientific means (including analyzing the archaeological record)". (FAHLANDER, 2014, p. 2), we must add to this total skepticism analysis of the present as well: sociology cannot establish 'how it is' and neither can the hard sciences, with their use of symbolically representative models and artificially construed lab machinations get through to the truths of their inquiries. However this stance really doesn't address the notion of whether or not there exists a reliable ideology that could potentially explain the material evidence (structural in character, universal in scope), but only emphasizes that attempts to do are generally rife with pitfalls and never complete.

Perhaps because archaeology generally can't record first-hand, personalized oral accounts from the mouths of its human actors, it has been largely spared from the deadlock of ambiguity of postmodernism that has more solidly permeated the corpus of the social sciences. If there are ideas and/or ideologies present in the subjects they must be extracted physically and the physical provides a framework with a fixed dimensionality, as Fahlander explains:

Indeed, archaeology is in a sense less liable to judgemental relativism than many other humanist disciplines because it deals with material data. Material traces of the past are seldom randomly distributed, but deposited in more or less closed contexts and layers. They are thus locked in time and space relative to other objects, which restricts the number of reasonable interpretations. There are also means of strengthening or refuting an interpretation by appealing to independent analyses such as microscopic traces of use-wear, or analysing biological remains in terms of their isotopic or genetic composition. It thus seems that for most archaeologists the idea of archaeological 'facts' being historically situated is more about being self-aware and reflexive when interpreting the past rather than an argument that 'anything goes' (FAHLANDER, 2014, p. 3). 
So what then has been the effects of this profound epistemological skepticism on archaeology and material cultural studies? In the first place, it has shifted an enormous amount of attention towards and questioning of the researchers themselves - for even if we accept the fact that the material remains under questions must 'speak for themselves', it will in the end be the archaeologists, their institutions of research and their publishers arranging the selected evidence into a value-imbued, language-based narrative. In the same way that two very good doctors might arrive at two very different medical diagnoses based on the $\mathrm{X}$-rays scans, patient symptoms and their preferred methods of treatment, two very fine archaeologists will likely publish two very different reports on the same structural ruins, artefact or societal remnants under observation. This likelihood of inconsistency doesn't speak to a variation in the physical reality or even to the quality or expertise of the practitioner, but we should agree that their training and knowledge (doctors and archaeologists alike) make them more likely to be closer to a correct description, diagnosis or explanation than someone without that training. The variation speaks to the everpresent wiggle room amongst interpretations along the spectrum of informed analysis.

This then is the great contribution of postmodernism to archaeology: a keener sense of needing to know the story (biographical background, academic training, intellectual influences, personal interests, political leanings of the researcher) behind the story: what is being said about the material culture. Surely in the case of the informer, the archaeologist, ideology (uppercased and lower-cased 'i' both included here) without a doubt informs the interpretative lens, excavation techniques, procurement of funding (archaeology is expensive), the political wrangling of publishing (the publishers often have different overall agendas of their own), research questions, etc. In fact, ideology is always a present force in any research in any field of inquiry, for none of these decisions, investments and procedures are performed in an ideologically-sealed vacuum.
Reseach develops in the noisy, emotive, politicallycharged, impassioned melee of an idea-driven human network. The 'postmodern turn' has helped make it ever more clear that to facilitate a fuller reading of the intended interpretation of the material evidence, as much knowledge about the archaeologist themselves will only contribute to our understanding of the published data. However it need not cause so much information overload as to render the whole epistemological operation futile - as a pure postmodernist might venture to claim.

Fahlander uses Roy Bhaskar's vocabulary to draw a clear distinction between the two approaches of skepticism: epistemological relativism acknowledges that all claims to knowledge are housed in a cultural, historical and ideological context (but it does not speak to the veracity of the claims). Judgemental relativism, on the other hand, involves giving an equal footing of validity and truthfulness to any knowledge-based claim (FAHLANDER, 2014, p. 3). If the later form were to be applied seriously to a research-based methodology like archaeology, the results would be an exciting creative anarchy, and in a bizarre way would bring the study of archaeology back to its antiquarian origins where the artifacts were often displayed in a hodgepodge manner to emphasize variation, induce shock and mesmerize the viewer with an overload of oddities. In this confetti-toss of material culture any structural underpinnings, rationale for the production of the artefacts or universal narratives regarding their creators is totally lost and intentionally ignored.

Here we now have two completely different schools of thought regarding the same subject (human material culture) and using the same vocabulary (ideology and archaeology) but pursuing entirely different lines of reasoning. The divisions put simply, as follows: a) Whether ideology reflects a single universal reality or only personalized imagined realities; b) Whether archaeology and the other social sciences can truly help to describe the nature of that reality or perhaps prove the lack of its universal presence; and c) What is the value of either of these approaches?

Perhaps this need not be a zero-sum game. 
Going back to our russian doll analogy - the famous russian carved toy only generates the amusement, interest and curiosity because of its multi-layered nature. It's quite possible to imagine enough intellectual space for one scholar to pursue the use of religion as a political control mechanism in 8th century maya city-states and another to investigate the ontological cosmology of the shaman priests' drug-induced, animal transformation ceremonies. In fact, either one of these studies would surely be enriched by the other, even though one is concerned with pure Voraussetzungen [real presuppositions] and the other with Vorstellungen fwhat individuals believe about themselves\} (RICOUER, 1986, p. 70-72). Now there certainly could be a valid discussion about which of these modes of inquiry would be more useful or relevant to our contemporary condition, and in a world where resources for research are scarce and in high demand, this is certainly a necessary debate. However, this in no way reflects on the intellectual integrity of the research topic itself. Ideally, we would have our telescopes aimed at the larger social structures and more individualized realities and beliefs under the microscope, so to speak: in the same way that astronomers might design rocket engines to reach the moon's surface to collect microscopic samples of lunar dust. Maintaining an interest in the science of interplanetary orbits does not prohibit investigation into surface-level details.

To stay amongst the splendid company of celestial bodies a bit longer, let us consider Althusser's image of 'The False Sunset' (which might be seen as a metaphorical cousin to Plato's cave). Throughout humankind's time on the planet references in both symbolic and mental form have built up regarding the sun's "setting" and "rising" behavior (an inaccurate use of the terms) and we now understand a more astronomically accurate version of the event could be used to describe the nature of the phenomena more correctly. The question remains however, whether the 'perspective'-based description of the stirringlybeautiful, tear-inducing sunset has no place in the official datalog if we have the coordinates and rate of rotation tables adjusted to predict the planetary movements for the next million years. This leads to the question of the value of subjectively-imbued data, the filter of language and the construction of narrative, an issue which postmodernism wrestles with directly.

Another of Fahlander's major claims regarding postmodernism's effects on archaeology has been the deconstructing of grand narratives. This is a trend that has direct ties towards the skepticism and downright hostility displayed towards ideologies over the course of the second half of the last century. It's not difficult to divine why when you realize most of the major ideological families have been strongly associated with specific currents of ugliness performing under their banner: economic liberalism - the exploitation and abuse of peripheral nations; socialism - the violent means with which socialist-inspired nations have controlled their populations; darwinism - its association with a 'survival of the fittest' conception of political power; catholicism - sexual predation and ostentatiously paradoxical displays of wealth. It's important to realize that these very reality-based critiques do not necessarily address the truthfulness of the ideology being espoused, but nevertheless, the die has been cast and ideologies and the grand narratives associated with each one of them (trickle down economics, the class struggle, evolutionism, spiritual salvation through Christ), have been largely dis-endowed of the general reliability once bestowed upon them by large sectors of society.

But we should also add here structuralism - the concept so central to our discussion - defined here as a general belief in some set of overall, organizing principles governing human societies. Although it does not have a linear grand narrative of its own, as such, it has been conceived of as an ideology in its own right and after going through a transformed rendition of post-structuralism, it nevertheless has been offered up as dead effigy to the bonfire of the postmodernists.

While some strains of postmodernism allow that truth may exist, while maintaining that there is no way to verify absolute principles, a major 
factor in their skepticism towards claims to truth and the dissolution of the grand narratives describing truths over time - what Koselleck calls 'transcendental' truths' - has been the realization that narratives are told from a specific perspective. Specifically, in the case of grand narratives that attempt to speak for all people, in all places, at all times; these 'storytellers' must be in positions of enormous power for their perspectives to have such a wide-reaching audience.

These power-bearing narrative devices can be as subtle as the language being used, the underpinning assumptions going unmentioned or structuring the paradigm in a way that leaves alternatives untenable. Foucault says that, 'Knowledge tends to follow a regime of truth', and likewise Fahlandar: "In postmodern epistemology, truth and knowledge is generally understood as something that is produced within a dominant discourse". (FAHLANDAR, 2014, p. 2).

So, likewise, in archaeology, the explanatory grand narratives have all been put to the test and forced to rethink their main premises in light of post-processual criticisms. This includes, but is certainly not limited to: the diffusionist model (attempts to track the spread of behaviors and practice over time and place); the evolutionary model (sees societies following general trends in technological development despite differences in context); the anthropological model (hoping to arrive at understanding thru a comparative analysis of cultures); and the environmental determinist model (which offers the surrounding environment as the determinant factor in a culture's development).

One counter-behavior or approach to the overbalance and affixed nature of the grand narrative/truthful ideology model has been a total emphasis on the individual stories embedded within the archaeological record. These researchers are fully embracing the concept that the optically-driven and emotionally invested view of the 'False Sunset' from the early evening beachcomber does have epistemological value and can be a valid research subject. Terry Eagleton is critical of this move away from knowledge that can apply to all and sees it as a bit of an intellectual escape route: "If the more abstract questions of state, class, mode of production, economic justice, had proved for the moment too hard to crack, one might always shift one's attention to something more intimate and immediate, more sensuous and particular" (EAGLETON, 1996, p. 17).

In dealing with individuals, the researcher themselves become more flexible in their use of subjectivity in their interpretations: and how could it be any other way? Anyone who has even been in a relationship knows how hard at times it can be to 'understand' your own partner, but giving general relationship advice to a friend is a much less daunting, and sometimes enjoyable, task. In this way, the postmodern humanities turn towards a postmodern liberality of research subject/ researcher relationship has given the work a more bi-laterally invested hue. In some cases, it feels as if the researcher is unknowingly revealing more about their own inner psychology than the reality of their research subjects: "The discipline of archaeology is one way our contemporary society constructs social memory within both dominant and counterhegemonic discourses. An archaeological focus on memory is grounded in larger cultural phenomena, including modernist anxieties, postmodern subjectivities, social traumas, and the rise of identity politics" (VAN DYKE, 2011, p. 233).

And that is not to say, that this post-processual, anti-ideological, individualized, postmodernist tendency is not without its true merits. Individuals certainly have been largely missing from the archaeological literature (apart from political leaders, etc.); but that was precisely because the researchers were genuinely not interested in their biographic stories! The goal was precisely to find larger truths that could help construct meaning about the way people have lived and developed as societies and that these truths might be applied in a meaningful way. Tracking the individual perspectives and exceptional behavior of each member of a society was not the primary goal of archaeology for the large majority of its development, and neither is this the case today. But, 
yes, certainly perspective-based subjects are valid for investigation, although considering the nature of the archaeological record, where data points are few and far between, it presents a methodological enigma: how does one get 'biographical' with material remains? One approach has been a Geertz-like vocabulary of symbols, but again this would require a universally accepted 'dictionary' of meaning: "many strands of post-processual archaeology betray a certain inconsistency when they argue for social heterogeneity and multivocality (individual experiences) at the same time as they advocate hermeneutics as a means to understand social collectives (cultures) as wholes" (FAHLANDER, 2014, p. 5).

And Fahlander also notes that these micronarratives, by the very nature that they are produced within an ideological framework tend to congregate around one of the dominant grand narratives that were initially under the lens of criticism. This puts the postmodernist researcher in the awkward position of having to recognize, at least tangentially, the presence of an ideology they were at pains to disregard.

So where does all of this leave the possibility of archaeology performing a necessary role in our pursuit of making sense out of the human condition? In a very good, even conditional, place I would argue. If 'history is the science of experience', as Koselleck (2018, p. 4) claims, than archaeology is an attempt to divine the procedure and purpose of a controlled experiment with no lab report, no publications or interviews with the participating researchers and, as is often the case, the use of units of measurements and equipment of unknown function and value: it is endeavoring to recreate the details of an infinitely complicated experiment of history by only studying the bustedup remnants of the lab.

This is a really difficult, time-consuming and expensive task and methodologies most continuously be tinkered with and improved upon in each new case. However, it is precisely the difficulty of working within the stubborn confines of materiality that gives archaeology and material culture studies in general, their epistemological edge. The fact that there is no pre-delivered explanation, no Joseph Campbell-like story arch and no culpatory mincing of the facts is exactly what makes the measurement, collection and interpretation of the material environment so reliable. This is why homicide detectives go to the scene of the crime even after having apprehended the murder suspect and getting his written affidavit: the material record tells its own version of the events. A postmodern police force would be ineffective, short-lived crimesolving agency indeed.

To 'make sense' of material reality we have developed language and language is a very powerful, but clumsy device. Narratives, small or large, and ideology (when developed honestly) are attempts to describe the happenstance of reality in a sensible way. It is ripe to be corrupted, misunderstood, downright incorrect and blinded by teleology, ignorance and connivances - but it is all we have got. Despite the challenges presented by the postmodernist stance, material culture studies and its historically-oriented sidekick, archaeology, are the basis on which our shared and individualized narratives sit. It should be championed as such and expanded in scope, approach and practical application as it engages the criticisms of postmodernity and continues to provide solidity in a seemingly chaotic world.

\section{REFERENCES}

ALTHUSSER, Louis. On the Reproduction of Capitalism: Ideology and Ideological State Apparatuses. London: Verso, 1971.

CAMPBELL, Joseph. The Hero With a Thousand

Faces. Princeton: Princeton University Press, 1949.

EAGLETON, Terry. The Illusions of Postmodernism. Oxford: Blackwell Publishing, 1996.

FAHLANDER, Fredrick. Postmodern Archaeologies. Oxford Handbooks Online, Oxford University Press, 2014. https://doi.org/10.1093/oxfordhb/9780199567942.013.014.

GEERTZ, Clifford. The Interpretation of Cultures New York: Basic Books, 1973.

KOSELLECK, Reinhart. Sediments of Time: On Possible Histories. Stanford: Stanford University Press, 2018.

LATOUR, Bruno. Reassembling the Social. Oxford: Oxford University Press, 2005. 
10/10 Oficina do historiador, Porto Alegre, v. 13. n. 1, p. 1-10, jan.-jun. 2020 | e-36727

RICOUER, Paul. Lectures on Ideology and Utopia.

New York: Columbia University Press, 1986.

VAN DYKE, Ruth M. Imagined Pasts Imagined: Me-

mory and Ideology in Archaeology. In: VAN DYKE,

Ruth M. Ideologies in Archaeology. Tucson: The

University of Arizona Press, 2011, p. 233-253.

\section{John Gabriel O'Donnell}

Mestrando em História pela Pontifícia Universidade Católica do Rio Grande do Sul - PUCRS

\section{Mailing address:}

John Gabriel O'Donnell

Pontificia Universidade Católica do Rio Grande do Sul

Avenida Ipiranga, 6681, Prédio 40

Partenon 90619-900

Porto Alegre, RS, Brasil 